\title{
Capílul 15
}

\section{Modelagem conceitual do sistema de emissão de ordens polca com uso da técnica IDEF-SIM}

\author{
Daniel Ribeiro Gomes' \\ Stella Jacyszyn Bachega ${ }^{3}$ \\ Natália Cibele de Sousa Santos ${ }^{2}$
}

Resumo: A elaboração de um modelo conceitual é uma etapa de extrema importância para se realizar um estudo de simulação, visto que tal modelo facilita a visualização e a interpretação do sistema que está sendo estudado, além de auxiliar a construção do modelo computacional. Dentre as técnicas de modelagem conceitual está o IDEF-SIM. O presente artigo tem o objetivo de elaborar o modelo conceitual de parte de uma linha de produção de uma empresa automobilística, representando seu funcionamento com o sistema de emissão de ordens POLCA. Para tal, utilizou-se nesta pesquisa a abordagem mista quantitativa e qualitativa, bem como os procedimentos de pesquisa revisão bibliográfica e estudo de caso. Constatou-se que a técnica IDEF-SIM apresentou ser uma técnica de fácil compreensão em relação aos conceitos e simbologias utilizados, o que facilitou a representação e o entendimento do modelo conceitual desenvolvido.

Palavras-chave: Modelagem Conceitual. POLCA. IDEF-SIM.

1 Universidade Federal de Goiás - UFG. Regional Catalão, Unidade Acadêmica Especial de Engenharia. Contato: daniel.ribg@gmail.com. Programa Institucional Voluntário de Iniciação Científica (PIVIC).

2 Universidade Federal de Goiás - UFG. Regional Catalão, Unidade Acadêmica Especial de Engenharia. Contato: naticibele_sousa@hotmail.com. Programa Institucional Voluntário de Iniciação Científica (PIVIC).

3 Universidade Federal de Goiás - UFG. Regional Catalão, Unidade Acadêmica Especial de Engenharia. Contato: stella@ufg.br. 


\section{Introdução}

As empresas, atualmente, se deparam com diferentes métodos e técnicas que podem auxiliar a tomada de decisão. Dentre estes está a simulação. Assim, organizações dos mais variados portes vem fazendo uso da técnica de simulação, que é definido por Harrel et al. (2002) como um processo de experimentação com um modelo detalhado de um sistema real. O intuito é determinar como o sistema se comportará a alterações em seu ambiente, estrutura, ou condições de contorno. Esta técnica é advogada por diversos autores como Berends e Romme (1999), Buffa e Sarin (1987), Chwif e Medina (2007), Freitas Filho (2008) e Law e Kelton (2000). Ainda, Sargent (2011) afirma que os modelos de simulação são cada vez mais usados para resolver problemas e para ajudar na tomada de decisões.

Entre as etapas sugeridas por Law e Kelton (2000), para um estudo de simulação, está a coleta de dados e definição do modelo. É nesta etapa que se elabora o modelo conceitual. Perera e Liyanage (2000) afirmam que a modelagem conceitual pode aumentar a qualidade de modelos de simulação, e ainda reduzir o tempo gasto para a construção destes modelos computacionais. Por este motivo, autores como Chwif, Paul e Barreto (2006), Greasley (2006), Perera e Liyanage (2000) e Ryan e Heavey (2006) apresentam uma interligação entre as ferramentas de mapeamento de processos e projetos de simulação em seus trabalhos.

Para Sargent (2011), um modelo conceitual deve ser constituído com o objetivo de facilitar a visualização e interpretação do sistema que está sendo estudado. Para tal, pode-se fazer usos de esquemas, pseudocódigos, fluxogramas, diagramas entre outros. Segundo Leal et al. (2009), para elaboração de um modelo conceitual, pode-se utilizar a técnica IDEF-SIM (Integrated Definition Methods - Simulation). Esta técnica facilita o trabalho encontrado na fase de modelagem computacional, pois o modelo conceitual é construído de uma forma que a lógica almejada pelo especialista em simulação é mantida. Além disso, esta é uma lógica de modelagem conceitual focada em projetos de simulação, fazendo uso de técnicas de modelagem já reconhecidas dentro do contexto do BPM (Business Process Modeling).

Baseado neste contexto, o objetivo do presente artigo é elaborar o modelo conceitual de parte de uma linha de produção de uma empresa automobilística, representando seu funcionamento com o sistema de emissão de ordens POLCA (Paired-cell Overlapping Loops of Cards with Authorization). Este sistema é parte de uma estratégia chamada QRM (Quick Response Manufacturing), discutida por Suri $(1998,2010)$.

É válido salientar que esta é uma das pesquisas do Grupo de Estudos em Modelagem e Simulação (GEMS). O presente artigo enquadra-se no projeto de pesquisa intitulado "Método para escolha de sistemas de coordenação de ordens com uso de simulação: aplicação em ambientes de produção flow shop". 
O artigo está estruturado como segue: na seção um apresenta-se a revisão bibliográfica; na seção dois há a metodologia utilizada na pesquisa; na seção 3 é apresentado o modelo conceitual do POLCA aplicado à realidade da empresa foco do estudo; na última sessão estão as considerações finais.

\section{Referencial Teórico}

Nesta seção, há uma breve revisão bibliográfica sobre sistemas de emissão de ordens, seguida do sistema POLCA e sobre a técnica IDEF-SIM.

\subsection{Sistemas de emissão de ordens}

Correa et al. (2001) definem o planejamento e controle da produção (PCP) como um processo usado no gerenciamento das atividades de produção, que administra os recursos operacionais de produção de uma empresa. Envolve funções de planejamento, programação e controle. Bem como, decidir o que, quanto e quando comprar e produzir, quais recursos serão utilizados e essencialmente controlar toda a produção.

Erdmann (1994), ao afirmar que as atividades do PCP se dividem em planejamento, programação e controle, define que a função de planejamento representa as atividades a longo prazo e que servem de suporte para a programação. Já a programação e o controle da produção, são funções direcionadas para o médio e curto prazo. Possuem a tarefa de definir as necessidades de materiais, as quantidades a serem fabricadas, as capacidades do sistema de produção e a liberação de ordens.

No mesmo seguimento, Chiavenato (2008) informa que a última etapa do PCP é controlar a produção. Esta etapa envolve acompanhar, analisar e regular as ações produtivas, pretendendo certificar se o que foi executado saiu como o planejado e se os objetivos foram atingidos.

Os Sistemas de Emissão de Ordens (SEO's), assim nomeados por Burbidge (1990), fazem parte das atividades de controle da produção. Tais sistemas auxiliam no monitoramento de liberação de ordens de produção no chão de fábrica. Burbidge (1983) afirma que tal liberação de ordens objetiva enviar as ordens de produção para o Plano Mestre de Produção (PMP). Onde é realizado a melhor estruturação de produção possível, procurando cumprir o período de entrega determinado de uma forma eficiente e eficaz.

A liberação das ordens de produção, nos sistemas de Planejamento e Controle da Produção mais difíceis, se encarrega de tomar providências de produção como: retirada de matéria-prima, substituições, contagem e entregas de peças produzidas (RUSSOMANO, 1979).

Para este fim, os SEO's objetivam auxiliar no controle de liberação de ordens de produção no chão de fábrica. Os quais são sistemas de comunicação que orga- 
nizam as necessidades de materiais e controlam a liberação das ordens de fabricação e compra.

Burbidge (1983) classifica os SEO's em três grupos distintos, a saber: (i) sistemas para fazer de acordo com o pedido; (ii) sistemas de estoque controlado. Sistemas em que o nível de estoque de cada produto é controlado separadamente dos demais e independente do Plano Mestre de Produção; (iii) sistemas de fluxo controlado. Sistemas que definem as necessidades de itens, a partir do Plano Mestre de Produção.

A escolha do sistema de emissão de ordens é de extrema valia para uma empresa e vale ressaltar que é importante levar em consideração o tipo de sistema de produção em que o Sistema de Emissão de Ordens irá operar. Dentre os SEO’s está o sistema POLCA.

\subsection{Paired-cell overlapping loops of cards with authorization (POLCA)}

O sistema POLCA, anexo da estratégia QRM (Quick Response Manufacturing), busca reduzir o lead time da empresa através da combinação dos sistemas de produção puxada e produção empurrada (SURI, 1998).

No sistema de produção empurrada a produção se inicia antes da ocorrência da demanda pelo produto, a produção depende de uma ordem enviada anteriormente. O sistema de Planejamento das Necessidades de Materiais (MRP) é um exemplo de produção empurrada. Já o sistema que "puxa" a produção, autoriza a liberação de trabalhos com base no status do seu nível de estoque. A demanda gerada pelo cliente é que dispara a produção. O Kanban, que é um sistema que controla o fluxo de materiais e informações através de cartões de produção e movimentação, é um sistema de produção puxada (SURI, 1998).

Os sistemas Kanban e MRP não são apropriados para os ambientes com fabricação de produtos personalizados e com demanda variável. Diante disso, Krishnamurthy e Suri (2003) relatam que o sistema POLCA busca utilizar as melhores características dos dois sistemas de produção (Kanban e MRP). Sendo assim, o fluxo de controle de ordens ao longo de duas células de produção é monitorado através de autorizações de liberação e por cartões de controle de produção (denominado cartão POLCA).

Suri (1998) e Fernandes e Godinho Filho (2007) relatam que o POLCA apresenta quatro características principais: i) a autorização de liberação de materiais é gerada via HL/MRP (High Level Material Requirement Planning); ii) o método de controle de material é fundamentado em um cartão, utilizado para comunicar e controlar o deslocamento de materiais entre as células (denominado cartão POLCA); iii) os cartões POLCA referem-se a um par de células ao contrário de se referirem a um só produto; iv) o cartão POLCA, para cada par de células, mantêm com a tarefa em todo o tempo de seu processamento através das duas células e posteriormente retorna 
para a primeira célula no momento em que é finalizado o processamento na segunda célula. Nesse instante, a primeira célula pode começar outra tarefa.

O número de cartões POLCA para cada loop pode ser definido usando uma simples aplicação da Lei de Little. A definição do número de cartões é feita através da seguinte equação (SURI, 1998):

$$
\text { Número de cartões } A / B=[L T(A)+L T(B)] \times N U M(A, B) / D
$$

\section{Onde:}

- $\quad$ LT (A): lead time da célula A;

- $\quad$ LT (B): lead time da célula B;

- $\operatorname{NUM}(\mathrm{A}, \mathrm{B})$ : número de trabalhos que vão da célula A para a célula B durante o período de planejamento;

- D: dias de trabalho durante o horizonte de planejamento.

Caso a equação resulte em um número fracionário, o resultado deve ser arredondado para o próximo valor inteiro.

A Figura 15.1 faz uma representação esquemática do funcionamento do POLCA em um sistema produtivo formado por quatro conjuntos de células de produção - Células X, Y, Z e W. No exemplo em questão, o produto será realizado seguindo o caminho X1, Y2, Z3 e W1. Apesar de o cartão POLCA permanecer com a tarefa dentro da célula em que está sendo processada, o fluxo de materiais entre as estações de trabalho na célula pode ser controlado através de outro sistema, como o Kanban. Dependendo da quantidade de ordens que serão produzidas, cada um dos ciclos pode ser guiado por um ou mais cartões POLCA. Neste caso, são definidos os ciclos X1/Y2, Y2/Z3 e Z3/W1. Este sistema trabalha com um método de autorizações iniciado por um MRP que imprime o roteiro de produção que acompanha o trabalho a ser feito e contém as informações necessárias para a produção daquele determinado item/produto (SURI, 1998).

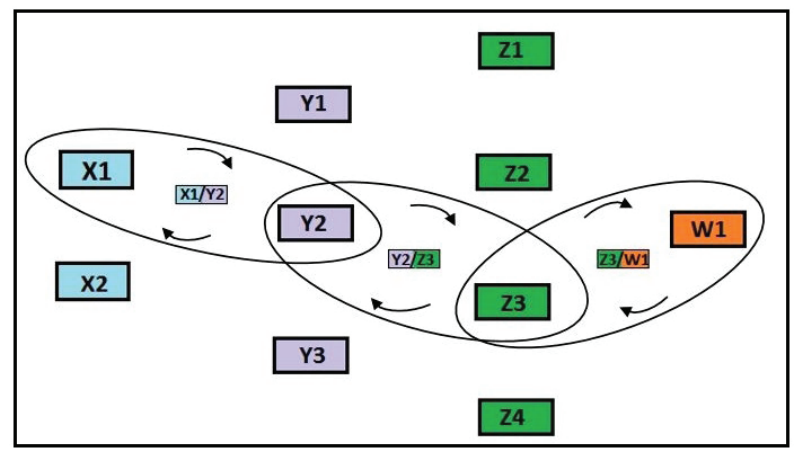

Figura 15.1 Funcionamento do Sistema POLCA

Fonte: Adaptado de Suri (1998). 
Ainda conforme a Figura 15.1, o processo é iniciado na Célula X1 desde que haja matéria-prima disponível em X1 e um cartão POLCA X1/Y2, indo em sequência à célula Y2. Assim, acontece sequencialmente para os outros cartões estabelecidos neste processo. Depois que uma célula completa suas operações, o produto da tarefa e o cartão POLCA X1/Y2 vão para o buffer de entrada da Célula Y2, indicando que um movimento é necessário, ou que material está disponível para uma próxima operação. Após chegar à Célula Y2, como esta tarefa é destinada à Célula Z3, é necessário que se tenha um cartão POLCA Y2/Z3 disponível para que esta operação seja iniciada (SURI, 1998).

É válido ressaltar que no POLCA o cartão X1/Y2 permanece com a tarefa ao longo da Célula Y2, juntamente com o cartão Y2/Z3. Isto mostra que na Célula Y2 haverá 2 cartões para aquela determinada tarefa, como parte de ciclos de 2 cartões. Sendo assim, cada tarefa na Célula Y2 levará 2 cartões POLCA consigo. Quando o trabalho é terminado na Célula Y2, ocorrem duas situações: i) o cartão $\mathrm{X} 1 / \mathrm{Y} 2$ é destacado da tarefa e é devolvido ao começo da Célula X1; ii) a tarefa é entregue ao buffer de entrada da Célula Z3 com o cartão Y2/Z3 ainda fixado de modo visível no material que está sendo processado (SURI, 1998).

$\mathrm{O}$ mesmo processo se repete para a célula de montagem $\mathrm{Z3}$, que necessita de um cartão Z3/W1 disponível para iniciar a tarefa na célula. Quando a tarefa é completada, esta segue para o buffer de entrada de W1, enquanto o cartão Y2/Z3 volta para o início da célula Y2. Como W1 é a última célula do roteiro, não haverá um cartão POLCA esperando para iniciar a produção e a tarefa pode ser lançada em W1 toda vez que a célula estiver preparada para iniciar outra tarefa. Quando a tarefa em W1 é completada, ela é expedida (considerando que a célula W é uma célula de expedição) e o cartão Z3/W1 retorna para o início de Z3, concluindo assim a jornada de cartões POLCA para esta ordem de produção (SURI, 1998).

Diante do funcionamento exposto, cada célula só iniciará seu trabalho, exceto a primeira e última célula, se houver um cartão que relacione a célula em questão com a célula anterior, e um cartão que relacione a presente célula com a célula posterior, além de ter o trabalho autorizado pelo sistema HL/MRP, de acordo com Suri (1998). O uso de cartões POLCA conforme descrito, garante que as células trabalhem em tarefas para a qual elas têm capacidade e ainda asseguram que a célula posterior também tenha capacidade para realizá-las.

\subsection{Integrated Definition Methods - Simulation (IDEF-SIM)}

De acordo com Sargent (2011), a modelagem conceitual deve ser feita para facilitar a visualização e a interpretação do sistema em estudo. Dessa forma, podem-se utilizar esquemas e expressões verbais que descreve sua dinâmica, destaque suas funções e as regras pré-estabelecidas. Todavia, a construção do modelo 
conceitual baseado em uma linguagem peculiar poderá impossibilitar a compreensão do modelo por uma pessoa que não tenha conhecimento do software utilizado. Como também, o uso do fluxograma, por exemplo, dificulta o entendimento da modelagem devido à falta de recursos para retratar determinados elementos próprios dos sistemas simulados.

Nesse seguimento, Leal et al. (2009) e Montevechi et al. (2010) propõem uma técnica de modelagem conceitual, denominada IDEF-SIM (Integrated Definition Methods - Simulation). Esta técnica foi criada devido à falta de técnicas de modelagem conceitual com foco na simulação. O IDEF-SIM tem como proposta que o modelo conceitual seja construído de modo que mantenha a lógica esperada pelo especialista em simulação.

O Quadro 15.1 traz a simbologia utilizada na técnica IDEF-SIM. Conforme Leal et al. (2009) e Montevechi et al. (2010), tal simbologia foi adaptada de elementos lógicos que são empregados em outras técnicas de modelagem (IDEF0 E IDEF3). Além da elaboração de novos elementos, a técnica proposta proporciona a elaboração de modelos conceituais com informações que simplificam a elaboração dos modelos computacionais e facilitam a compreensão do projeto.

Quadro 15.1 Símbolos utilizados no IDEF-SIM

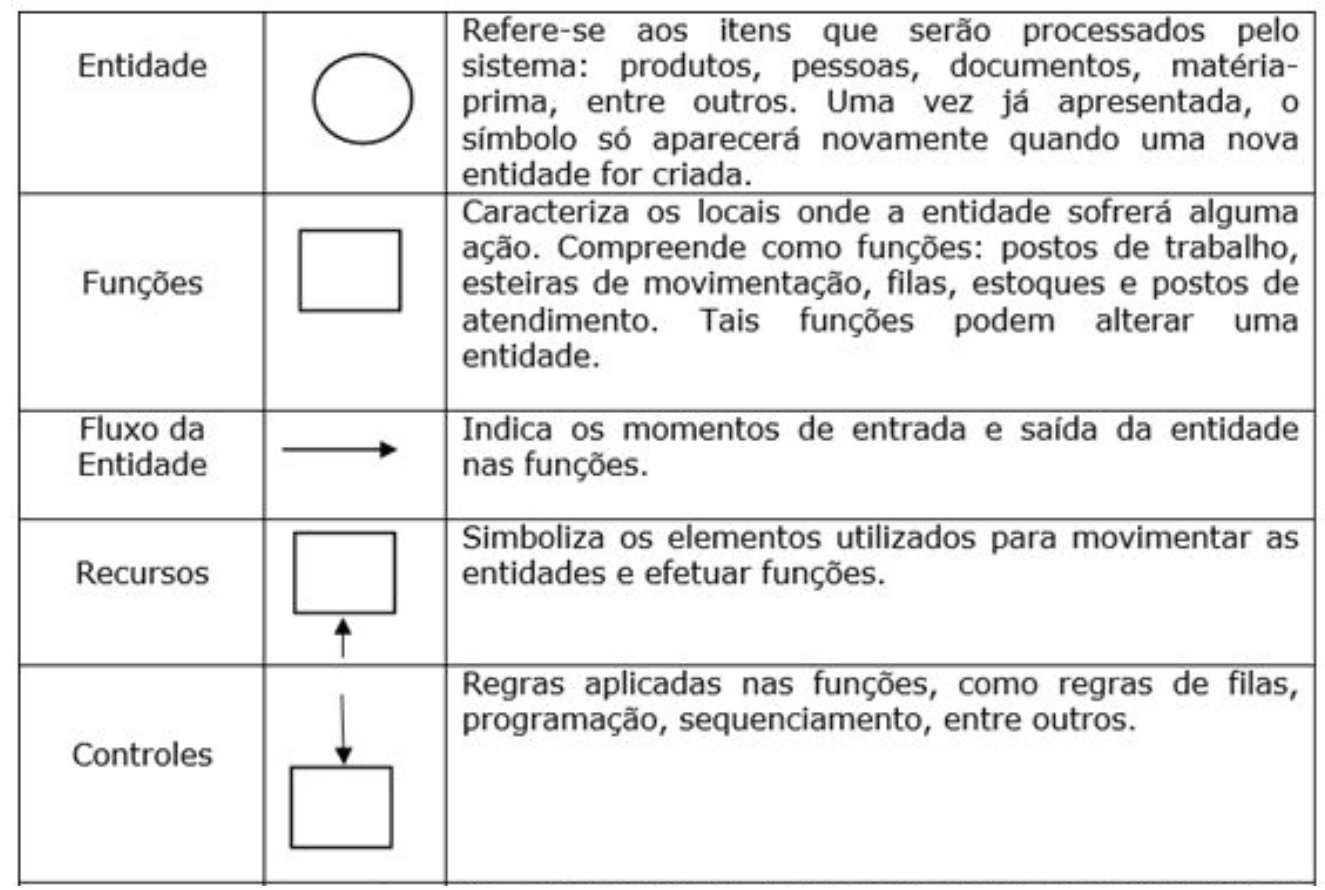


Quadro 15.1 Símbolos utilizados no IDEF-SIM (Continuação)

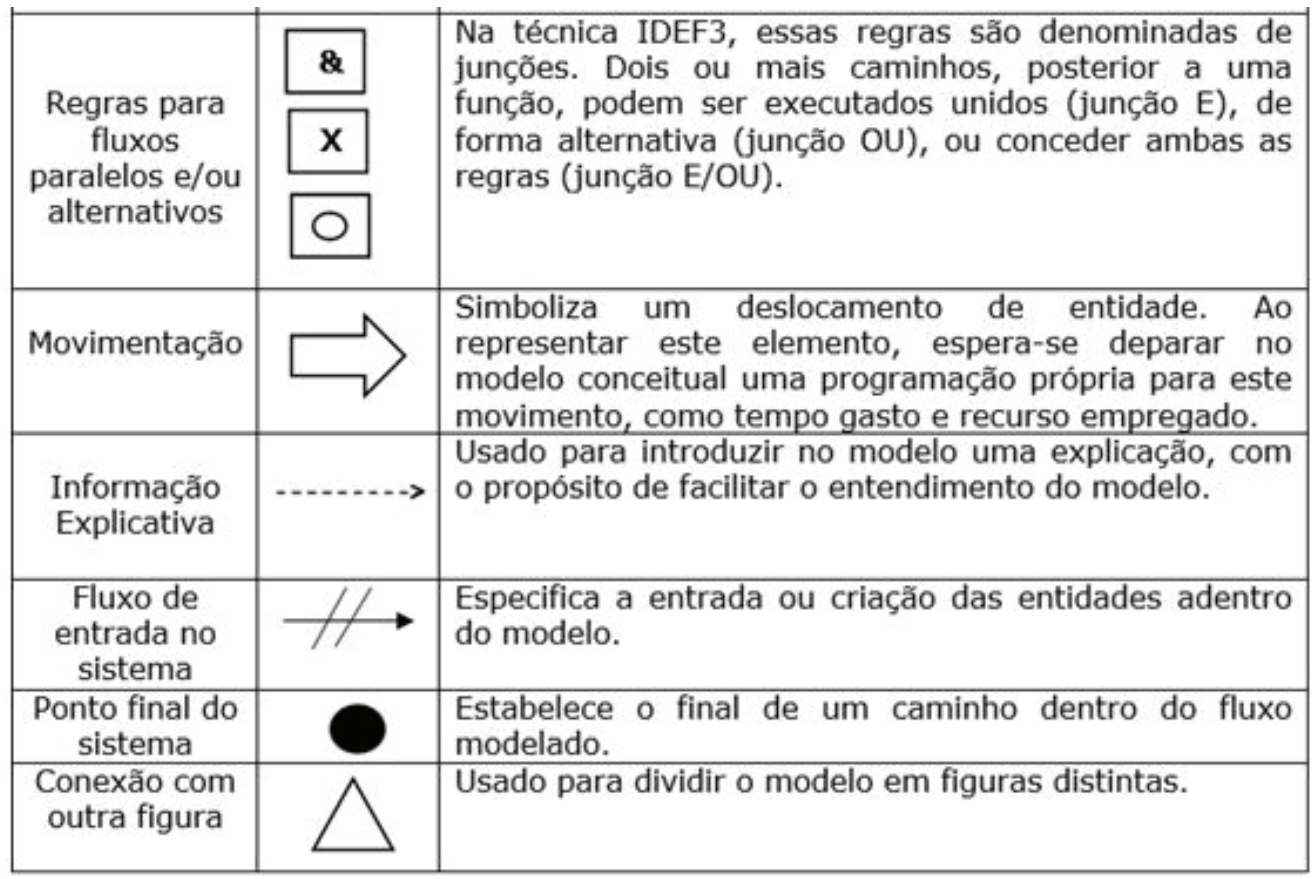

Fonte: Adaptado de Leal et al. (2009) e Montevechi et al. (2010)

\section{Metodologia}

De acordo com Bryman (1989), a pesquisa pode ser categorizada baseada em duas abordagens a saber: quantitativa e qualitativa. Segundo Freitas et al. (2000), diversas vezes pode-se combinar o uso de diferentes métodos, beneficiando-se de duas fontes de coleta de dados, aliando a abordagem qualitativa com a quantitativa. Nesta pesquisa, a abordagem mista foi empregada, devido a forma como os dados coletados e informações geradas foram tratados.

Quanto aos procedimentos de pesquisa, foi aplicada a revisão bibliográfica e o estudo de caso. Segundo Webster e Watson (2002), a revisão bibliográfica é primordial para dar início a qualquer pesquisa científica. Este procedimento foi utilizado com intuito de pré-orientação teórica. Ainda, foi utilizado o estudo de caso (YIN, 1990) para propiciar a compreensão da realidade da empresa montadora de automóveis. Nota-se que a parte estudada na empresa foi a linha de montagem de eixos traseiros. 
Os dados utilizados nesta pesquisa foram coletados in loco (no próprio local), por meio de entrevistas e observações e podem ser classificados como de natureza secundária. Dados secundários são classificado por Hair Jr. et al. (2005) como um conjunto de dados históricos ou coletados anteriormente para um problema de pesquisa distinto da pesquisa atual.

Para a elaboração do modelo conceitual, utilizou-se neste trabalho a técnica IDEF-SIM, proposta por Leal, Almeida e Montevechi (2008). A qual apresenta um conjunto de funções e técnicas de modelagem conceitual com foco na simulação. Para a validação do modelo conceitual desenvolvido, foi usada a validação face-a-face, conforme Sargent (2011).

Utilizou-se o software $D I A^{\circledR}$ para construir o modelo conceitual por meio da técnica IDEF-SIM. Este software permite a construção de layouts, fluxogramas e diagramas em geral, com diversos objetos e recursos.

\section{Discussão e Resultados}

O modelo conceitual foi elaborado com base em dados coletados em uma parte da linha de produção de uma empresa do setor automobilístico. A parte dessa linha em questão refere-se à produção de eixos. A linha de produção possui cinco estações de trabalho sequenciais, onde, a estação 2 possui dois operadores trabalhando simultaneamente, e as demais operam com somente um operador em cada. Os tempos de movimentação entre as estações de trabalho são valores muito pequenos, sendo que tal valor é agregado no tempo de operação de cada operador e não representado como uma movimentação significativa no modelo.

Os operadores seguem instruções de processo para realização de suas atividades. Ainda, na linha de produção há a possibilidade de entrada de sete modelos diferentes, respeitando o estabelecido na ordem de produção. Todos os modelos passam obrigatoriamente em todas as estações de trabalho, sendo que cada modelo possui um tempo diferente de processamento, com exceção da estação 5 em que os tempos de processamento são iguais para todos os modelos.

De posse de todas essas informações e com auxílio da técnica IDEF-SIM, pôde-se desenvolver o modelo conceitual, foco deste estudo, mostrado na Figura 15.2. A legenda dos elementos utilizados encontra-se nos Quadros 15.2 e 15.3 . 

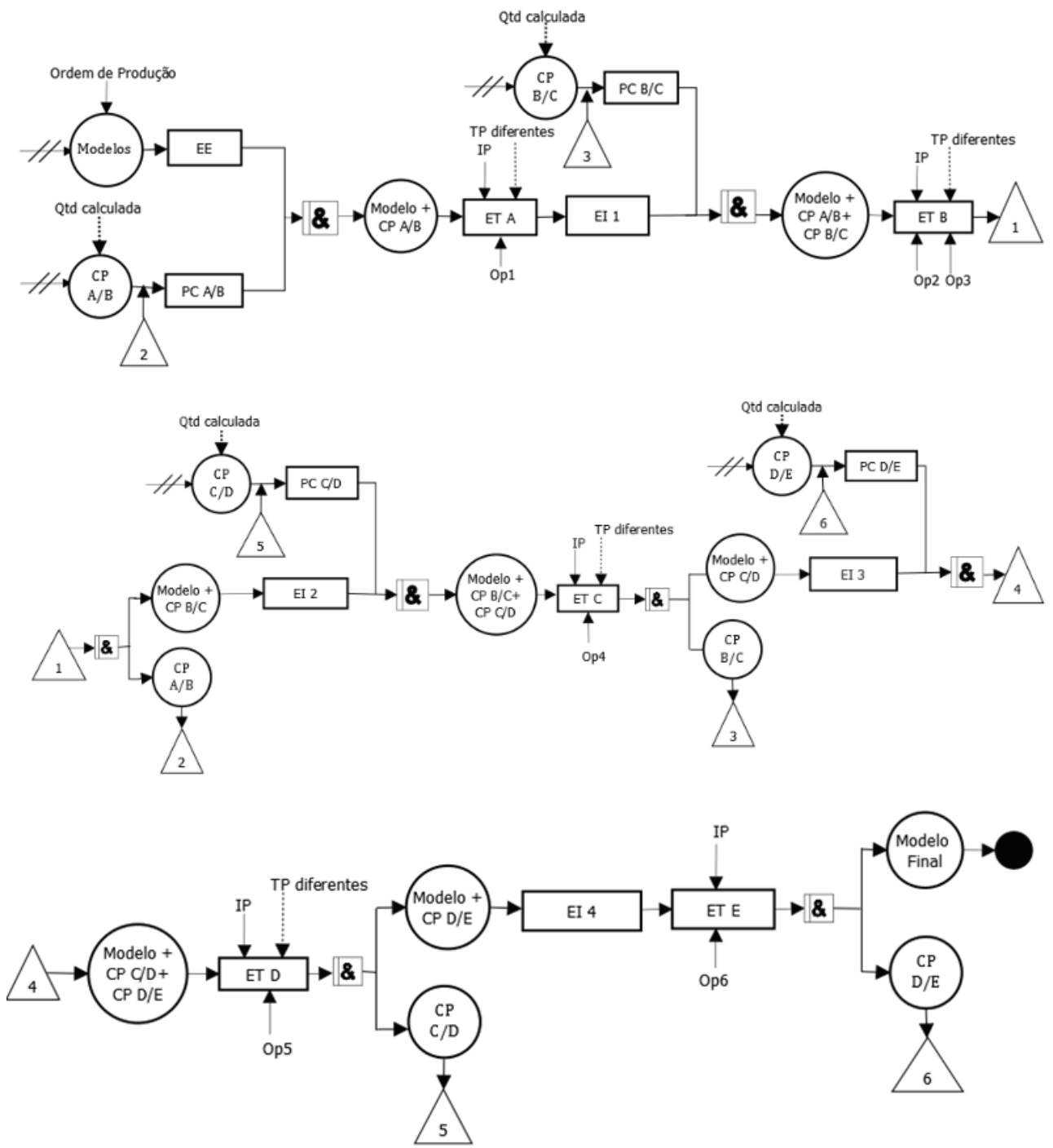

Figura 15.2 Modelo Conceitual POLCA com uso do IDEF-SIM

Fonte: Elaborada pelos autores.

Quadro 15.2 Legenda dos elementos utilizados no IDEF-SIM (Parte 1)

\begin{tabular}{|l|l|l|l|l|}
\hline \multicolumn{1}{|c|}{ Entidades } & \multicolumn{1}{|c|}{ Nome } & \multicolumn{1}{|c|}{ Funções } & \multicolumn{1}{c|}{ Nome } \\
\hline Modelos & Modelos de eixo & EE & Estoque de Entrada \\
\hline CPA/B & Cartão Polca A/B & El n & Estoque Intermediário $n$ \\
\hline
\end{tabular}


Quadro 15.2 Legenda dos elementos utilizados no IDEF-SIM (Parte 1) (Continuação)

\begin{tabular}{|c|c|c|c|}
\hline Entidades & Nome & Funções & Nome \\
\hline $\mathrm{CPB} / \mathrm{C}$ & Cartão Polca B/C & $\mathrm{PCA} / \mathrm{B}$ & Posto de Cartões A/B \\
\hline$C P C / D$ & Cartão Polca C/D & $P C B / C$ & Posto de Cartões B/C \\
\hline CPD/E & Cartão Polca D/E & $P C C / D$ & Posto de Cartões C/D \\
\hline Modelo+ CPn & $\begin{array}{l}\text { Junção de um modelo n com } \\
\text { um cartão POLCA n }\end{array}$ & $P C D / E$ & Posto de Cartões D/E \\
\hline Modelo final & Modelo de eixo finalizado & $\mathrm{ET} n$ & Estação de trabalho n \\
\hline
\end{tabular}

Fonte: Elaborado pelos autores.

Quadro 15.3 Legenda dos elementos utilizados no IDEF-SIM (Parte 2)

\begin{tabular}{|l|l|l|l|l|}
\hline \multicolumn{1}{|c|}{ Recursos } & \multicolumn{1}{|c|}{ Nome } & \multicolumn{1}{|c|}{ Informações } & \multicolumn{1}{c|}{ Nome } \\
\hline Op n & Operador $\mathrm{n}$ & $\mathbb{P}$ & Instruçōes de processo \\
\hline & & TP & Tempo de processamento \\
\hline
\end{tabular}

Fonte: Elaborado pelos autores.

Quando um modelo de eixo chega à linha de produção, representado no modelo conceitual pelo Estoque de Entrada, se houver um cartão POLCA A/B disponível no posto de cartões, este cartão será anexado no eixo, o que resulta na entidade 'Modelo+CP A/B', e a entidade seguirá para estação de trabalho A para ser processada. $\mathrm{Na}$ estação de trabalho A há apenas um operador, que segue instruções de processo e os tempos de processamento de cada modelo são diferentes. Percebe-se que as quantidades de cartão são calculadas para cada posto, por meio da Equação 1, e os modelos de eixo chegam à linha baseado em ordens de produção.

Após a entidade ter completado as operações necessárias na estação de trabalho A, esta segue para o estoque intermediário 1, onde aguarda até que um cartão POLCA B/C esteja disponível no posto de cartões B/C. Quando um cartão POLCA B/C fica disponível, este cartão é anexado no item, o que gera a entidade 'Modelo+CP A/B+CP B/C', que segue para ser processada pela estação de trabalho B. Nesta estação existem dois operadores que também seguem instruções de processo para realizar suas atividades de forma simultânea. Cada modelo de eixo gasta um tempo diferente para ser processado nesta estação. 
Ao se terminar as atividades necessárias na estação de trabalho $\mathrm{B}$, o cartão POLCA A/B é retirado do modelo de eixo e retorna para o posto de cartões A/B. $\mathrm{A}$ entidade 'Modelo+CP B/C' segue então para o estoque intermediário 2, e fica aguardando a disponibilidade de um cartão POLCA C/D no posto de cartões C/D. No momento que este cartão fica disponível, ele é anexado no modelo de eixo, e assim a entidade 'Modelo+CP B/C+C/D' segue para ser processada na estação de trabalho $\mathrm{C}$, com tempos diferentes de processamento para cada modelo de eixo e com apenas um operador, que segue as instruções de processo.

Esta mesma lógica de processamento acontece nas demais estações de trabalho. Ressalta-se que o tempo de processamento é constante para todos os tipos de modelo de eixo na estação de trabalho $\mathrm{E}$ e que as movimentações foram representadas como sendo somente fluxo de entidade, porque é uma atividade realizada pelo próprio operador de cada uma das estações e se dá em uma pequena fração de tempo.

Pode-se notar também que, após processamento na estação de trabalho $\mathrm{D}$, a entidade 'Modelo+CP D/E segue para o estoque intermediário 4. Neste ponto do sistema não há um cartão POLCA esperando para iniciar a produção e a entidade pode seguir para ser processada na estação de trabalho E sempre que esta estação estiver preparada para iniciar uma nova atividade. Quando a atividade da estação de trabalho E é completada, o modelo de eixo acabado deixa a linha de produção e o cartão POLCA D/E retorna para seu posto de cartões de origem, concluindo assim a jornada de cartões POLCA para esta ordem de produção.

\section{Considerações finais}

Os objetivos inicialmente propostos foram alcançados. A modelagem conceitual do sistema de emissão de ordens POLCA foi realizada por meio do uso da técnica IDEF-SIM. Para a construção do modelo conceitual, foram utilizados dados de uma linha de produção de eixos traseiros de uma empresa automobilística, além de uma revisão bibliográfica sobre o sistema de emissão de ordens POLCA e sobre a técnica IDEF-SIM.

Por meio desta pesquisa, a técnica IDEF-SIM se apresentou como uma técnica de fácil compreensão em relação aos conceitos e simbologias utilizados, o que promoveu a representação e o entendimento do modelo conceitual elaborado.

Como a escolha da técnica de modelagem conceitual é de extrema importância para um estudo de simulação, este trabalho contribuiu para a comunidade acadêmica como também para a comunidade empresarial, ao passo que apresentou aplicação prática de uma técnica que auxilia na construção de modelos conceituais voltados para a posterior programação computacional dos modelos de simulação. Ainda, promove a divulgação e uma melhor 
compreensão da técnica IDEF-SIM, a qual é um suporte para o estudo de simulação, tendo em vista que a simulação é um método que pode auxiliar as empresas em processos decisórios.

Por fim, para pesquisas futuras, sugere-se que seja realizada a simulação do modelo conceitual apresentado neste trabalho. Ainda, é possível elaborar novos modelos conceituais e de simulação considerando cenários com uso de outros sistemas de emissão de ordens, e compará-los para avaliação do desempenho destes no ambiente produtivo estudado.

\section{Referências}

BERENDS, P.; ROMME, G. Simulation as a research tool in management studies. European Management Journal, v.17, n.6, pp.576-583, 1999.

BRYMAN, A. Research methods and organization studies. $1^{a}$ ed. London: Uniwin Hyman, 1989. 224 p.

BUFFA, E. S.; SARIN, R. K. Modern Produtction/Operations Management. $8^{\mathrm{a}}$ ed. John Wiley \& Sons, 1987.

BURBIDGE, J. L. Planejamento e controle da produção. São Paulo: Atlas, 1983.

BURBIDGE, J. L. Production Control: a universal conceptual framework. Production Planning and Control, vol. 1, n.1, pp. 3-16, 1990.

CHIAVENATO, Idalberto. Planejamento e Controle de Produção. São Paulo: Manole, 2008.

CHWIF, L.; MEDINA, A. C. Modelagem e Simulação de Eventos Discretos: Teoria e Aplicações. São Paulo: Bravarte. 2ª ed. 2007.

CHWIF, L.; PAUL, R. J.; BARRETTO, M. R. P. Discrete event simulation model reduction: A causal approach. Simulation Modelling Practice and Theory, v. 14, n. 7, p. 930-944, 2006.

CORRÊA, H. L.; GIANESI, I. G. N.; CAON, M. Planejamento, Programação e Controle da produção. 4. ed. São Paulo: Editora Atlas, 2001

ERDMANN, R. H. Modelo organizativo para sistemas de planejamento e controle da produção. 1994. 309 f. Tese (Doutorado em Engenharia da Produção) - Pro- 
grama de Pós-graduação em Engenharia da Produção - UFSC, Santa Catarina, 1994.

FERNANDES, F. C. F. GODINHO FILHO, M. Sistemas de coordenação de ordens: revisão, classificação, funcionamento e aplicabilidade. Gestão e Produção, São Carlos, v. 14, n. 2, 2007.

FREITAS FILHO, P. J. Introdução à modelagem e simulação de sistemas. Florianópolis: Visual Books. 2a ed. 2008.

FREITAS, H. et al. O método de pesquisa survey. Revista de administração, v. 35, n. 3, p. 105-112, 2000.

GREASLEY, A. Using process mapping and business process simulation to support a process-based approach to change in a public sector organisation. Technovation, v. 26, n. 1, p. 95-103, 2006.

HAIR JR., J. F.; ANDERSON, R. E.; TATHAM, R. L.; BLACK, W. C. Análise multivariada de dados. $5^{\mathrm{a}}$ ed. Porto Alegre: Bookman, 2005. 595 p.

HARREL, C. R.; MOTT, J. R. A.; BATEMAN, R. E.; BOWDEN, R. G.; GOGG, T. J. Simulação: otimizando os sistemas. São Paulo: Belge Simulação e IMAM. $2^{\mathrm{a}}$ ed. 2002.

KRISHNAMURTHY, A.; SURI, R. How to Plan and Implement POLCA: A Material Control System for High-Variety or Custom-Engineered Products. Wisconsin, Madison: Center for Quick Response Manufacturing, 2003. Technical Report.

LAW, A. M.; KELTON, W. D. Simulation Modeling \& Analysis. 3rd edition, New York: McGraw- Hill, 2000.

LEAL, F.; OLIVEIRA, M. L. M.; ALMEIDA, D. A.; MONTEVECHI, J. A. B. Desenvolvimento e aplicação de uma técnica de modelagem conceitual de processos em projetos de simulação: O IDEF-SIM. In: Encontro de Engenharia de Produção, 29, 2009, Salvador. Anais... Salvador: ABEPRO, 2009. p. 14.

MONTEVECHI, B. A. J.; LEAL, F.; PINHO, F. A.; COSTA, S. F. R.; OLIVEIRA, M. L.M.; SILVA, F. L. A. Conceptual Modelling In Simulation Projects By 
Mean Adapted Idef: An Application In A Brazilian Tech Company. In: 2010 Winter Simulation Conference, 2010, Baltimore. Proceedings... Baltimore: IEEE, 2010. p. 1624-1635.

PERERA, T.; LIYANAGE, K. Methodology for rapid identification and collection of input data in the simulation of manufacturing systems. Simulation Practice and Theory, v. 7, n. 7, p. 645-656, 2000.

RIEZEBOS, J. Design of POLCA material control systems. International Journal of Production Research, vol. 48, n. 5, p. 1455-1477, 2010.

RUSSOMANO, V. H. Planejamento e Acompanhamento da Produção. São Paulo: Ed. Pioneira, 1979.

RYAN, J; HEAVEY, C. Process modeling for simulation. Computers in industry, v. 57, n. 5 , p. $437-450,2006$.

SARGENT, R. G. Verification and validation of simulation models. In: 2011 Winter Simulation Conference, 2011, Phoenix. Proceedings... Phoenix: IEEE, 2011. p. 183-198.

SURI, R. It's about time: the competitive advantage of quick response manufacturing. New York: Productivity Press, 2010.

SURI, R. Quick response manufacturing: a companywide approach to reducing lead times. Portland: Productivity Press, 1998.

WEBSTER, J.; WATSON, J.T. Analyzing the past to prepare for the future: writing a literature review. MIS Quarterly \& The Society for Information Management, v.26, n.2, pp.13-23, 2002.

YIN, R. K. Case study research: design and methods. Sage Publications Inc., USA, 1990. 
